\title{
Interpreting Complex Arrhythmias: Part III
}

Editors

GIUSEPPE BAGLIANI

ROBERTO DE PONTI

FABIO M. LEONELLI

\section{CARDIAC \\ ELECTROPHYSIOLOGY CLINICS}

www.cardiacEP.theclinics.com

Consulting Editors

RANJAN K. THAKUR

ANDREA NATALE

June 2019 • Volume 11 - Number 2 